July 2021

"Water Allocation, Crop Choice, and Priority Services"

François Salanié and Vera Zaporozhets 


\title{
Water Allocation, Crop Choice, and Priority Services*
}

\author{
François Salanié ${ }^{\dagger} \quad$ Vera Zaporozhets ${ }^{\ddagger}$
}

July 6, 2021

\begin{abstract}
We analyze the problem of allocating irrigation water among heterogenous farmers when water supply is stochastic. If farmers are risk-neutral, a spot market for water is efficient; while the oft-used uniform rationing system is inefficient, both ex-ante and ex-post. Indeed, we show that it leads farmers to overexpose to risk, thus making shortages more severe and more frequent in case of drought. We propose instead a regulation by priority classes extending Wilson (1989), and we derive an efficiency result. We characterize the set of farmers that would win or loose from such a reform. We also argue that a system of priority classes may be preferred to a spot market system, because scarcity is easier to manage ex-ante than ex-post, and because this system facilitates the supply of insurance to risk-averse agents.
\end{abstract}

*The authors acknowledge funding from ANR under grant ANR-17-EURE-0010 (Investissements d'Avenir program). We have benefitted from discussions in various seminars; in particular, we thank Dominique Bureau and Katrin Erdlenbruch for useful comments. The first author also acknowledges financial support from the research foundation TSEPartnership.

${ }^{\dagger}$ Toulouse School of Economics, INRAE, University of Toulouse Capitole, Toulouse, France.

†TTulouse School of Economics, INRAE, University of Toulouse Capitole, Toulouse, France. Corresponding author: vera.zaporozhets@inrae.fr 
Keywords: Water, Irrigation, Priority Classes, Rationing.

JEL Codes: Q15, Q25, D47.

\section{Introduction}

Some resources, such as water for irrigation, are subject to severe supply shocks, and this feature makes it difficult to allocate them across competing uses. While economists often advocate markets as a solution, it is fair to acknowledge that they also raise practical and theoretical difficulties, and that other systems may sometimes perform as well. This article proposes to consider the institution of a priority class system, when it comes to solving the difficult and important problem of allocating irrigation water across users.

Let us recall that agriculture relies on irrigation to produce $42 \%$ of crop output, and is responsible for $70 \%$ of total water withdrawals (FAO, 2012). An unfortunate consequence is that agricultural water demand contributes significantly to water scarcity during droughts. In addition, climate change is expected to aggravate the severity and duration of droughts in many regions (UN, 2012 and 2015; IPCC, 2014; Swain et al., 2018). These considerations have led various countries to examine reforms of water allocation systems in order to make them more robust to uncertain supplies. ${ }^{1}$

Indeed, irrigation is often managed thanks to coarse regulatory instruments such as rationing. These instruments are economically inefficient, as they do not allocate water supply to the most productive users. Consider for example the French system. In this country, farmers have to apply for yearly irrigation licenses, which specify a reference volume that can be extracted at each location. In the river basins that have adopted volumetric water management, water is allocated to users proportionally to these licenses (Lefebvre et al., 2014). Short-term policies for managing water scarcity include tempo-

\footnotetext{
${ }^{1}$ The adaptation of agriculture to water scarcity and climate change is listed among the key objectives of European water and agriculture regulation (e.g., WFD, 2000/60/EC and EC, 2013).
} 
ral restrictions of water use (such as night irrigation) which are implemented by the prefects. Between 2011 and 2014, there were 8950 prefectural decisions to introduce temporary restrictions in 1320 zones. The concentration of these decisions on certain zones is striking. $50 \%$ of zones got less than 5 decisions each, $25 \%$ saw more than 10 decisions, and $3 \%$ got more than 30. Among the 100 French departments, 4 departments got more than 500 decisions. ${ }^{2}$ It is apparent that the system does not work well, as some zones face almost permanent restrictions on water use, even in rainy years (Erdlenbruch et al., 2013). Similar remarks apply to many countries. The absence of a price system is seen by many observers as the main cause of the actual crisis in global water management (Barbier, 2019).

An alternative would be to create water markets, which should allocate water efficiently, even when supply is scarce. It turns out that water markets are not widely implemented, with a few exceptions such as in Australia (Connor and Kaczan, 2013; Grafton et al., 2015), in the western states of the USA (Hagerty, 2019), and in Chile (Howitt, 1998; Bjornlund and McKay, 2002). In reality, multiple market failures, difficulties associated with implementation, and sometimes political obstacles, have lead to the adoption of various other systems, depending on the objectives of water authorities (Davidson et al., 2019).

In this paper, we propose an alternative system aiming at a better balance between efficiency, complexity, and social acceptability. A few priority classes are created. Ex-ante, typically in fall, farmers register in a class by paying the corresponding price. Ex-post, in spring or summer, once the water supply is observed the members of the highest priority class are first served, and then the members of the second highest priority class, and so on until all available water is allocated.

Priority classes ensure that high value users have a higher probability of receiving water, which is good for efficiency. In fact, in a framework

\footnotetext{
${ }^{2}$ Based on own calculations using data from http://propluvia.developpementdurable.gouv.fr/propluvia/faces/index.jsp.
} 
with 0/1 demand, Chao and Wilson (1987) and Wilson (1989) show that such a priority system achieves all the efficiency gains attributed to spot markets. This system was implemented in the electric power industry to manage peak demand and the consumers' reliability needs. In practice, the difficulty is often to determine the prices that apply to different levels of reliability, in different places, and for different periods (Strauss and Oren, 1993; Beenstock and Ephraim, 1997). Industrial users sometimes also want to choose different reliability levels for different equipments. These requirements raise technical difficulties that are specific to the management of a power distribution network. ${ }^{3}$ Our contribution is to derive a general efficiency result in an extended setup, specifically adapted to water allotment in irrigation. In particular, since different crops may be more or less vulnerable to the lack of water, we allow farmers to book different water quantities in each priority class, and we indicate how to compute the price of a unit of water in each priority class. This application of priority classes to irrigation management has not been proposed so far in the literature.

A key argument in our analysis is that the choice of a management system for allocating scarce water resources affects the crop mix, as farmers entitled to more water shift land towards water intensive crops, and crop yields become more sensitive to droughts (Hornbeck and Keskin, 2014). We show that when switching from uniform rationing to a market system or to a priority class system, the farmers that use water less productively reduce their irrigated area and their water consumption, and conversely more productive farmers use more water to irrigate a larger area. The allocation of water is shown accordingly to become more efficient.

The system of priority classes not only brings efficiency gains but also helps avoid the difficulties associated to the functioning of spot markets. One of these difficulties is that the spot price is highly volatile, for structural

\footnotetext{
${ }^{3}$ See Crampes and Lefouili (2019) for the analysis of a recent incident that lead to an interruption of service for some consumers. Astier (2021) discusses the trade-offs involved when using price schedules that may be more or less complex. For a recent reference on priority classes, see Gershkov and Winter (2020).
} 
reasons: nobody needs irrigation water when there is plenty, and everybody needs it when there is none. Demand and supply are thus negatively correlated, due to climate shocks. Clearly, highly volatile spot markets create political difficulties in case of droughts, since a major conflict has to be settled in a period of time when actors experience a major negative shock. By contrast, the priority system settles these conflicts ex-ante. As we shall see, it also allows for an easier sharing of risks among farmers than the complete system of contingent markets theoretically required by a market system.

We proceed as follows. In Section 2 we set up a general model in which heterogenous farmers choose ex-ante their exposure to risk, i.e., the share of their land devoted to water-dependent crops. Ex-post, after the climate shock has realized, the available water supply is allocated among farmers, according to some institutional system. In Sections 3 and 4, we examine the properties of two such systems, the spot market system and the uniform rationing system respectively. We define efficiency ex-post as the best manner to allocate water among farmers, for given crop choices; while efficiency ex-ante includes the definition of optimal crop choices. We show that the uniform rationing system is inefficient not only ex-post, but also ex-ante, by inducing farmers to select water-dependent crops.

In Section 5, we introduce the system of priority classes, which extends Wilson (1989) to general demand functions, and we provide conditions under which the system of priority classes is as efficient as a market system. These conditions are more likely to be satisfied in small basins - incidentally, notice that for such basins a spot market would not be liquid enough. Next, in Section 6, we show that the switch to an efficient system benefits both the less productive and the very productive farmers, for different reasons. The less efficient farmers did not irrigate much before the switch as they were not very productive for irrigated crops. Switching to an efficient system is thus not very costly for them. Conversely, very productive farmers increase their profits by expanding their irrigated area. In Section 7 we consider some extensions. With risk averse farmers, full efficiency requires that risks are 
shared efficiently. Consequently, we investigate the case when an insurance company offers insurance against the risk of loss due to the unavailability of water, and does so at actuarially fair rates. Finally, we conclude in Section 8 with a brief discussion and give some directions for future research.

\section{Model}

A hydrographic basin is populated by a continuum of heterogenous farmers, indexed by a parameter $\theta \in[\underline{\theta}, \bar{\theta}]$, with a cumulative distribution function $F$ over this interval. Each farmer owns a given land area, that can be devoted to two different crops with different needs for water. An institutional system allocates a stochastic supply of water among farmers. The timing is as follows.

Ex-ante, typically in fall of a given year, each farmer chooses the area $x$ that he devotes to the water-dependent crop. More generally, because water supply is risky, $x$ can be seen as the farmer's choice of risk exposure.

The basin is then affected by a random state of nature $s$, i.e., a complete description of technological possibilities. Hence, $s$ may contain information on, e.g. temperature, or the rainfall on each field. It also determines the total water quantity $Q(s)$ (from rivers or groundwater) available for irrigation. We let $E$ denote the expectation operator with respect to the distribution of $s$, and we suppose that thanks to past chronicles this distribution is known by all agents.

Ex-post, typically in spring or summer of the following year, the quantity $Q(s)$ is allocated among farmers, according to one of the following institutional systems: either a spot market for water, or a uniform rationing rule, or a system with priority classes. We shall discuss the relative efficiency of these three systems, based on their impact on the farmers' payoffs.

Farmers are assumed to be risk-neutral with respect to monetary revenue; this assumption will be relaxed in Section 7. Farmer $\theta$ gets a revenue

$$
B(q, x, s, \theta)-t
$$


when he receives $q$ units of water in state $s$, his risk exposure level is $x$, and he has to pay $t$. We adopt the following assumption (subscripts denote partial derivatives):

Assumption 1 Function B is twice differentiable, increasing in q, and strictly concave in $(q, x)$. Moreover, for each $(q, x, s, \theta)$ we have:

$$
q B_{q}+x B_{x} \text { is increasing in } q .
$$

The first part of the assumption ensures that the farmer's demand function $D$ for water is well-defined as a function of the water price $p$ :

$$
B_{q}(q, x, s, \theta)=p \quad \text { if and only if } q=D(p, x, s, \theta) .
$$

Property (1) is studied at the beginning of the Appendix, where we provide three different characterizations of it. In particular, we show that it is equivalent to the following statement: the sum of the elasticity of water demand with respect to price $p$, and of the elasticity of demand with respect to area $x$, is at least one. This holds, for example, as soon as water demand is proportional to the irrigated area $x$.

Finally, we define the homogenous case as the benchmark case in which all farmers are identical, so that the surplus $B$ and the demand $D$ do not depend on $\theta$ anymore. In this case, when all farmers choose the same value for $x$ ex-ante, the problem of allocating water ex-post is trivial: each farmer should get the same quantity $Q(s)$ in state $s$. However, the ex-ante effects on the choice of $x$ will be shown to depend on the system under study. The case of heterogenous farmers is more complex, and will sometimes be discussed through examples.

\section{$3 \quad$ Efficiency and the Spot Market}

In the absence of wealth effects and of risk-aversion, efficiency is simply defined by the maximization of the expected total surplus

$$
E \int_{\theta} B(q(\theta, s), x(\theta), s, \theta) d F(\theta)
$$


over the ex-ante decisions $x(\theta)$ and ex-post water consumption $q(\theta, s)$, subject to the feasibility constraint in each state $s$ :

$$
\int_{\theta} q(\theta, s) d F(\theta) \leq Q(s) .
$$

Under strict concavity of $B$ in $(q, x)$, the shadow price of water $p^{*}($.$) in$ each state $s$ and the solution $\left(x^{*}, q^{*}\right)$ are uniquely determined by the following equalities: ${ }^{4}$

$$
\begin{aligned}
q^{*}(\theta, s) & =D\left(p^{*}(s), x^{*}(\theta), s, \theta\right) \\
Q(s) & =\int q^{*}(\theta, s) d F(\theta) \\
0 & =E B_{x}\left(q^{*}(\theta, s), x^{*}(\theta), s, \theta\right) .
\end{aligned}
$$

Because there are no externalities, the second welfare theorem holds for this well-behaved economy. It is thus possible to decentralize this optimum, by allocating property rights on water in an arbitrary way, and by creating a spot market that opens ex-post to balance water supply and water demand at a price $p^{*}(s)$ in state $s$. Such a price system ensures the efficiency of private choices: each farmer can freely choose both his consumption of water $q$ and his irrigated area $x$ to maximize his profits

$$
E\left[B(q, x, s, \theta)-p^{*}(s) q\right]
$$

This dynamic efficiency result is a strong argument in favor of a market system. Finally, in the homogenous case, efficiency simply means that all farmers consume the same water quantity $Q(s)$ in each state $s$, and choose the same area $x^{*}$, with

$$
E B_{x}\left(Q(s), x^{*}, s\right)=0 .
$$

\footnotetext{
${ }^{4}$ For simplicity, we ignore the states of nature in which $Q(s)$ is so high that the shadow price of water is zero.
} 


\section{Uniform Rationing}

When water turns out to be scarce, one is naturally tempted to allocate it to the farmers that need it most, i.e., those that have ex-ante chosen a higher area of irrigated crops. We accordingly define uniform rationing as follows:

Definition: The uniform rationing rule allocates water in proportion to each observed irrigated area $x$.

The simplicity of this system may explain why it is so widely used in case of drought (see Barbier, 2019). The system involves no monetary transfers, and the irrigated area $x$ is easily observed. We now study the properties of such a system for allocating water.

Let $x(\theta)$ denote the irrigated area chosen by farmer $\theta$, and let $X=$

$\int x(\theta) d F(\theta)$ be the corresponding aggregate area. Ex-post, given these choices and the state $s$, and according to the above definition, each farmer $\theta$ gets a constant share of the total supply $Q(s)$ :

$$
q(\theta, s)=\frac{x(\theta)}{X} Q(s)
$$

so that $Q(s)$ is fully allocated by construction. Ex-ante, farmers anticipate the value of $X$, and given this anticipation each of them chooses $x$ to maximize

$$
E B\left(\frac{x}{X} Q(s), x, s, \theta\right) \text {. }
$$

Farmers now play a Nash equilibrium, instead of having their choices coordinated thanks to the water price. Under our concavity assumption, there exists a unique solution $x(\theta, X)$ to the above maximization problem. Moreover, we show in the beginning of the Appendix that this solution is decreasing with $X$, thanks to property (1). As a consequence, the equation

$$
\int x(\theta, X) d F(\theta)=X
$$


admits a unique solution $X^{R}$. Therefore, there exists a unique Nash equilibrium of the game, that we index with the subscript $R$. It is such that

$$
x^{R}(\theta)=x\left(\theta, X^{R}\right) \quad X^{R}=\int x^{R}(\theta) d F(\theta) \quad q^{R}(\theta, s)=\frac{x^{R}(\theta)}{X^{R}} Q(s) .
$$

To study this equilibrium outcome, we begin by the homogenous case, in which all farmers are identical and behave symmetrically. Given $X^{R}$, each farmer chooses $x$ to maximize

$$
E B\left(\frac{x}{X^{R}} Q(s), x, s\right)
$$

and by symmetry the solution must be such that

$$
q^{R}(s)=Q(s) \quad x^{R}=X^{R}
$$

The necessary and sufficient first order condition is therefore

$$
E\left[\frac{Q(s)}{x^{R}} B_{q}\left(Q(s), x^{R}, s\right)+B_{x}\left(Q(s), x^{R}, s\right)\right]=0 .
$$

Because $B$ is increasing with $q$, the first term is positive. Consequently:

$$
E\left[B_{x}\left(Q(s), x^{R}, s\right)\right] \leq 0 .
$$

Moreover, in the homogenous case the optimal irrigated area is characterized by (3). Since $B$ is concave in $x$, we conclude that $x^{R}$ must lie above $x^{*}:$

Proposition 1 In the homogenous case, the uniform rationing rule efficiently allocates water ex-post $\left(q^{R}(s)=q^{*}(s)=Q(s)\right)$, but it induces farmers to choose an over-optimal irrigated area $\left(x^{R} \geq x^{*}\right)$.

Ex-post efficiency obtains simply because the egalitarian allocation of water implemented by uniform rationing is optimal when farmers are identical. But uniform rationing is not ex-ante efficient: by allocating water as a function of ex-post needs, this rule encourages farmers to increase their irrigated 
area $x$, so as to be entitled to more water rights ex-post. This corresponds to an excessive exposure to the risk of drought.

In the case when farmers are heterogenous, the proportional allocation of water specified by uniform rationing is no longer ex-post efficient, as different farmers may have different productivities for water. This efficiency loss is thus higher when farmers are more heterogenous. However, this heterogeneity is at least partly endogenous, as it depends on the choice of $x$. To go further, we now study the question of efficiency more precisely, by means of an example.

Example 1: this example is based on the idea that even though land is heterogenous, each unit of land can be converted into efficiency units that are comparable across farmers. So assume that the irrigated land $x$ of farmer $\theta$ is equivalent to $a(\theta) x$ efficiency units of land, where $a(\theta)$ is a positive coefficient. Assume also that revenue per efficiency unit of land $b\left(q^{\prime}, s\right)$ is an increasing and strictly concave function of the water quantity $q^{\prime}$ made available for this unit, and in addition depends in an arbitrary manner of the state of nature $s$. When farmer $\theta$ has chosen $x$, and obtains $q$ units of water overall, he optimally allocates this quantity of water so that each efficiency unit gets $q^{\prime}=\frac{q}{a(\theta) x}$ water units, and therefore his revenue in state $s$ is the product of revenue $b\left(q^{\prime}, s\right)$ by the number of efficiency units, as follows:

$$
B(q, x, s, \theta)=a(\theta) x b\left(\frac{q}{a(\theta) x}, s\right)-c(x, \theta),
$$

where function $c$ is strictly convex in $x$, and represents costs associated to tractors or irrigation devices. Heterogeneity is introduced through two channels: farmers with a higher type $\theta$ are endowed with fields that are marginally more costly to irrigate (assume $c_{\theta x} \geq 0$ ), and that are less productive (assume $a(\theta)$ is nonincreasing with $\theta$ ). This specification yields a simple expression for water demand:

$$
D(p, x, s, \theta)=a(\theta) x d(p, s)
$$

where $d(p, s)$ is the demand function for water in state $s$ for each efficiency 
unit. $d$ is the inverse function of the first derivative $b_{1}$ of $b\left(q^{\prime}, s\right)$, and is thus decreasing with the water price $p$. In words, all farmers choose the same quantity of water $d(p, s)$ per efficiency unit of land. It is easily checked that this example satisfies our assumptions. The following result is proven in the Appendix:

Proposition 2 Assume Example 1 holds. The efficient irrigated land area $x^{*}(\theta)$ is decreasing with $\theta$. Under uniform rationing, the irrigated land area $x^{R}(\theta)$ is also decreasing with $\theta$, and there exist $\theta_{1}<\theta_{2}$ such that:

i) The most efficient farmers $\left(\theta \leq \theta_{1}\right)$ choose a suboptimal irrigated area $\left(x^{R}(\theta) \leq x^{*}(\theta)\right)$, and get a suboptimal amount of water per unit of irrigated land;

ii) Intermediate types $\left(\theta_{1} \leq \theta \leq \theta_{2}\right)$ choose an over-optimal irrigated area $\left(x^{R}(\theta) \geq x^{*}(\theta)\right)$, and get a suboptimal amount of water per unit of irrigated land;

iii) Relatively inefficient farmers $\left(\theta \geq \theta_{2}\right)$ choose an over-optimal irrigated area $\left(x^{R}(\theta) \geq x^{*}(\theta)\right)$ and get an over-optimal amount of water per unit of irrigated land.

Hence, uniform rationing exerts a differentiated effect on heterogenous farmers. The less efficient ones are given rights on water that they do not really need, and rationally react by increasing the share of land they irrigate. By contrast, this allocation of water is insufficient for the most efficient farmers, who react by reducing their irrigated area.

Strikingly, this differential treatment induces farmers to make more homogenous choices, as $x^{R}$ is too high when $x^{*}$ is low, and too low when $x^{*}$ is high. To the outside observer, farmers thus look more similar, which justifies in turn the use of a uniform rationing system, since it is ex-post efficient when farmers are identical. The system thus seems to create the conditions for its own perennity. Moreover, because the farmers' interests are more closely aligned, they are able to form a more effective interest group. ${ }^{5}$ Overall, we

\footnotetext{
${ }^{5}$ See Le Breton and Salanié (2003).
} 
conclude that the uniform rationing system presents specificities that explain why it is widely used, in spite of being inefficient both ex-ante and ex-post.

\section{Buying water in advance: priority classes}

In this section, we present a third institutional system, that we call priority classes. Ex-ante, farmers are invited to buy seats in a queue for water; expost, the water supply is allocated sequentially following the queue, until exhaustion. The idea is that better positions in the queue are costlier, and this leads farmers to make careful choices ex-ante about their crop mix.

Let us turn to more formal definitions. Ex-ante, a tariff $P($.$) is announced,$ and farmers are offered to buy at price $P(C)$ the $C^{\text {th }}$ unit of water. De jure, this unit will be delivered ex-post only if it is available, i.e., if $s$ is such that $Q(s) \geq C$. In the Walrasian tradition, no other payments or transactions are needed; all action thus takes place ex-ante.

We now characterize the tariff $P($.) that ensures the equality of supply and demand. The social value of the $C^{\text {th }}$ unit of water is the expectation of its social value $p^{*}(s)$ across states $s$, provided this unit is delivered. Hence, the natural tariff is

$$
P(C)=E\left[p^{*}(s) 1_{C \leq Q(s)}\right] .
$$

Unsurprisingly, higher priority seats (with a lower $C$ ) are sold at a higher price since the corresponding water units are more likely to be delivered. When facing this tariff, a farmer buys a portfolio of seats which can be represented by an increasing function $G$, such that $G(C)$ is the total quantity bought below the $C^{\text {th }}$ unit. For this portfolio, he pays in total:

$$
\int_{C} P(C) d G(C)=E\left[p^{*}(s) \int_{C \leq Q(s)} d G(C)\right]=E\left[p^{*}(s) G(Q(s))\right] .
$$

By doing so, he gets a water quantity $G(Q(s))$ in every state $s$. His expected profit is therefore

$$
E\left[B(G(Q(s)), x, s, \theta)-p^{*}(s) G(Q(s))\right]
$$


to be maximized over the function $G$ and $x$, under the constraint that $G$ is a non-decreasing function. This program can be compared to the program (2) defining efficient decisions. We see that the equality of demand and supply, and the efficiency of the final allocation, will obtain if and only if the efficient quantity $q^{*}(\theta, s)$ is a nondecreasing function of $Q(s)$ :

$$
q^{*}(\theta, s)=G(Q(s)) .
$$

This condition itself can be decomposed into two requirements. First, the efficient quantities $q^{*}(\theta, s)$ can depend on $s$ only through $Q(s)$. Intuitively, this is the main limitation of priority classes: by definition of this system, delivery is contingent on the realization of $Q(s)$ only, and cannot be made contingent on $s$ itself. We shall see below that this requirement is more likely to be satisfied when the basin is small, since in this case all agents are similarly impacted by climate shocks.

Second, $q^{*}(\theta, s)$ has to be nondecreasing with respect to $Q(s)$. Recall that these quantities add up to $Q(s)$ in each state, and therefore a higher $Q$ implies that at least some of the quantities have to increase. But a higher $Q$ also means that the weather is wetter, thus making irrigation water less needed, and one may conceive that efficient quantities are lower for some farmers.

We now argue that these requirements hold in a variety of settings. First, consider the homogenous case, in which optimal quantities are identical across farmers: $q^{*}(\theta, s)=Q(s)$. Then condition (8) is clearly satisfied, and we get:

Proposition 3 In the homogenous case, the priority system is efficient, provided prices are set as in (6).

Let us now extend this result to the case of heterogeneous farmers. Recall that we want each efficient demand to depend on $s$ only through $Q(s)$. One manner to obtain this property is to use the resource constraint that must hold in each state $s$ :

$$
\int D\left(p^{*}(s), x^{*}(\theta), s, \theta\right) d F(\theta)=Q(s) .
$$


To do so, assume the existence of real-valued functions $d$ and $a$ such that

$$
D(p, x, s, \theta)=d(a(p, s), x, \theta),
$$

with $a$ decreasing in $p$, and $d$ increasing with $a$. This assumption expresses that changes in the state of nature can be summarized in a single number $a$, which essentially captures the change in water supply. Notice that it holds in Example 1, as indicated by (5).

Then the resource constraint tells us that $a\left(p^{*}(s), s\right)$ depends on $s$ only through $Q(s)$, and is therefore equal to some function $\delta(Q(s))$, such that for all $Q$ the resource constraint holds:

$$
\int d\left(\delta(Q), x^{*}(\theta), \theta\right) d F(\theta)=Q .
$$

Therefore, $\delta$ is increasing with $Q$, and $q^{*}(\theta, s)=d\left(\delta(Q(s)), x^{*}(\theta), \theta\right)$ depends on $s$ only through $Q(s)$, and indeed increases with $Q$. Therefore (8) holds. We have shown:

Proposition 4 The priority system is efficient if condition (9) holds.

A second avenue is to assume directly that the demand for water $D$ depends on $s$ only through $Q(s)$, so that there exists a function $d$ such that:

$$
D(p, x, s, \theta)=d(p, x, Q(s), \theta) .
$$

This corresponds once more to the idea that the basin is small, and that $Q(s)$ is a sufficient statistic for $s$. Since in each state $s$ the spot price for water $p^{*}(s)$ is determined by equalizing the sum of demands to the supply $Q(s)$, then it must be that this price also depends on $s$ only through $Q(s)$. Moreover, since $q^{*}(\theta, s)$ equals the demand $d$ at the spot price $p^{*}(s)$, then this quantity also can depend on $s$ only through $Q(s)$, and therefore one can find a function $G$ such that (8) holds.

But this is not sufficient to conclude, because we need to make sure that this function is increasing. In its last part, the Appendix derives a condition 
under which this holds true.

To summarize, in each case the key assumption is that the state of nature impacts every farmer in a similar way: either because farmers are identical, or because $s$ matters only through a known function that does not depend on the farmer (as in (9)), or because $s$ matters only through $Q(s)$ (as in (10)). The priority class system thus better fits small-scale basins, for which climate shocks can be assumed to exert uniform effects on all farmers. In this case, it is plausible that efficient quantities only depend on total supply, as in (8).

The second requirement (that efficient quantities be increasing with water supply) sometimes requires additional assumptions on the profit functions. On the other hand, it can be ignored if farmers are allowed to both buy or sell in advance the $C^{\text {th }}$ unit (provided it has bought a $C^{\prime}$ unit, with $C^{\prime}<C$ ). Alternatively, the farmer could sell this unneeded unit ex-post, on a spot market that would open for settling such last-minute exchanges, or through direct bargaining with neighbors. Allowing for direct exchanges ex-post among farmers definitely promotes efficiency; the point in implementing a system of priority class is that such a system hopefully makes these exchanges much less needed.

\section{Winners and Losers}

The ex-ante and ex-post inefficiencies of uniform rationing support a reform towards a more efficient system. Still, even though aggregate wealth would be higher after such a reform, it is not so easy to redistribute these gains so that everybody is better off. In this section, we try to minimize informational requirements, and we accordingly assume that as one switches from uniform rationing to an efficient system, the money raised is redistributed to farmers in a lump-sum manner. The question we ask is whether we can characterize who are the winners and the losers from such a reform. 
Recall that under uniform rationing, the expected payoff of farmer $\theta$ writes:

$$
\mathcal{B}^{R}(\theta) \equiv E B\left(q^{R}(\theta, s), x^{R}(\theta), s, \theta\right) .
$$

Under a market system with redistribution, we define similarly

$$
\mathcal{B}^{*}(\theta) \equiv E\left[B\left(q^{*}(\theta, s), x^{*}(\theta), s, \theta\right)-p^{*}(s) q^{*}(\theta, s)\right]+E\left[p^{*}(s) Q(s)\right] .
$$

The last term corresponds to the lump-sum redistribution of revenues from water taxation. At this stage, notice that if we consider a priority class system instead, then each farmer's profit is still $\mathcal{B}^{*}(\theta)$. Indeed, when prices of seats are set as in (6), then each farmer ends up with the payoff in (7), and the money raised is exactly $E\left[p^{*} Q\right]$. The analysis below therefore applies to both cases.

To compare these two profit levels, first notice that we have

$$
E\left[B\left(q^{R}, x^{R}, s, \theta\right)-p^{*} q^{R}\right] \leq E\left[B\left(q^{*}, x^{*}, s, \theta\right)-p^{*} q^{*}\right],
$$

because by definition $\left(q^{*}, x^{*}\right)$ maximizes the expression in the right-hand side. We use the above definitions to get:

$$
\mathcal{B}^{R} \leq \mathcal{B}^{*}+E\left[p^{*} q^{R}-p^{*} Q\right] .
$$

In addition, under uniform rationing we have

$$
q^{R}(\theta, s)=\frac{x^{R}(\theta)}{X^{R}} Q(s),
$$

so that we obtain:

$$
\mathcal{B}^{R}(\theta)+\left(1-\frac{x^{R}(\theta)}{X^{R}}\right) E\left[p^{*}(s) Q(s)\right] \leq \mathcal{B}^{*}(\theta) .
$$

This yields the following result.

Proposition 5 Suppose one switches from uniform rationing to a market system, or to a priority class system, with lump-sum redistribution. If under uniform rationing a farmer's irrigated area is less or equal to the average area $\left(x^{R}(\theta) \leq X^{R}\right)$, then this farmer benefits from the reform. 
The generality of this result is striking: lump-sum redistribution is sufficient to compensate small-scale farmers for the reform. In fact, those farmers did not irrigate much, because they were not very productive for irrigated crops. Switching to an efficient system is thus not very costly for them, and the lump-sum redistribution of revenues more than compensates for the disappearance of the free water rights they held under uniform rationing. Conversely, one expects that very efficient farmers also benefit from the reform, but for a very different reason: after the reform, since they are very productive they can increase their profits by drastically expanding their irrigated area. This is indeed exactly what is happening in our Example 1, even in the absence of lump-sum redistribution.

Proposition 6 In Example 1, the most efficient farmers ( $\theta$ below $\theta_{1}$, as defined in Proposition 2) benefit from the reform, even in the absence of lump-sum redistribution.

Overall, the general picture is as follows. Farmers that did not irrigate much before the reform should support it because they will receive a sufficient lump-sum compensation. Farmers that expand their irrigated area after the reform should support it for efficiency reasons. Consequently, the opponents to the reform are likely to be found in an intermediate category which irrigated more than the average before the reform, and which still does so after the reform, so that their payments for water exceed the lump-sum redistributive term.

\section{Introducing risk-aversion and insurance}

So far, we have worked under an assumption of risk-neutrality that is admittedly very demanding, as farmers face important climate risks ex-post. This section argues that the provision of insurance can be integrated in the priority class system in a quite natural way. 
The first important remark is that any insurance system has to be based on an observable variable, such as the occurrence of a loss. It turns out that the priority class system requires to write delivery contracts that are contingent on the realization of the total supply $Q(s)$, as announced by some public authority. This announcement thereby makes this variable contractible. Private insurers may consequently use it as a basis for insurance contracts. In particular, a contract can specify that an indemnity be paid for each unit of water $C$ that was paid for ex-ante, but that was not delivered ex-post because supply was insufficient.

Let us study such a system formally. Assume that farmers are risk-averse, and endow each farmer $\theta$ with a concave Von Neumann-Morgenstern utility function. Assume also that each farmer's profits depend on $s$ only through $Q(s)$, so that there exists a function $b$ such that

$$
B(q, x, s, \theta)=b(q, x, Q(s), \theta)
$$

As in the previous section, every farmer can buy ex-ante a portfolio $G($. of water units, contingent on availability, for a monetary transfer computed using the tariff $P($.$) given in (6). In addition, we now allow each farmer to$ choose ex-ante a portfolio of indemnities $i($.$) , so that for each C$, the farmer gets $i(C)$ when the $\mathrm{C}^{\text {th }}$ water unit is not delivered, or equivalently when $Q(s)<C$. We assume that the insurance sector is competitive, so that the farmer pays ex-ante a fair premium that equals expected indemnities.

Overall, the farmer has to choose ex-ante the water portfolio $G(C)$ and the indemnities $i(C)$. The indemnities paid in state $s$ are

$$
I(Q(s)) \equiv \int_{C>Q(s)} i(C) d G(C)
$$

and interestingly they are a function of $Q(s)$ only. The fair premium is therefore $E I(Q(s))$. Overall, the farmer's payoff in state $s$ is

$$
b(G(Q(s)), x, Q(s), \theta)-\int P(C) d G(C)+I(Q(s))-E I(Q(s)) .
$$


Thanks to the assumption in (11), this profit depends on $s$ only through $Q(s)$. This makes it possible for the farmer to get full coverage of his risk, and in fact this is what the farmer aims at because insurance is fairly priced.The corresponding condition obtains by setting to zero the derivative with respect to $Q$ of the profit:

$$
i(Q) d G(Q)=b_{q} d G(Q)+b_{Q} .
$$

Moreover, and as already observed, if prices for seats $P($.$) are set as in (6)$ the farmer selects the efficient water quantities. This condition thus becomes

$$
i(Q(s))=p^{*}(s)+\frac{b_{Q}}{d G(Q(s))} .
$$

That is, the farmer faces two insurable risks. The first one is the risk that a unit of water is not delivered, and in the state $s$ corresponding to this unit the loss for the farmer is indeed $p^{*}(s)$. The second one is the risk associated to climate conditions: a reduction in $Q$ may be bad news, if it is associated to a less favorable weather, hence the second term in this formula. By asking for an indemnity for each water unit that fails to be delivered, the farmer can get full insurance, provided his profits depend on $s$ only through $Q(s)$, as specified in (11). Otherwise, coverage can only be partial, but it is still desirable, and the verifiability of $Q$ makes it easier to supply insurance.

\section{Discussion and concluding remarks}

We have discussed the properties of three different systems for allocating water. The most widely used is uniform rationing, but this system is inefficient, both for sharing water ex-post and for inducing farmers to choose the right mix of crops ex-ante. The spot market system is theoretically efficient, but it faces a few issues that complicate its implementation. Indeed, one defining feature of irrigation water is that nobody needs it when there is plenty, and vice-versa. In economic terms, supply and demand are strongly negatively correlated for evident climate reasons. This means that the spot price can 
take extreme values, from zero in periods of abundance to very high values in periods of drought. When the drought is severe, it is not socially and politically easy to implement such prices. ${ }^{6}$ Farmers may also anticipate ex-ante that the commitment to a market system is not credible and will be reneged ex-post.

For that matter, the priority class system has a big advantage over the spot market system: possible conflicts about water use are settled ex-ante, before total supply is known. It also forces farmers to anticipate that they may lack water, and to adapt their choices of crops accordingly. Finally, as we have shown, the priority system can be made as efficient as the spot market system, under conditions we discuss below.

In addition, the question of risk and insurance is in practice a very important one. Such considerations do not invalidate the market solution, but they call for opening new markets ex-ante. These contingent markets should allow for buying water that would be delivered only under some contingencies. The advantages to the farmers is that these markets allow for a better planning of their water needs, as well as a better sharing of risks with insurers. Another advantage of having such a system of markets is that more transactions are decided ex-ante, instead of being bargained ex-post. Nevertheless, one has to underline that creating even a few more markets is not an easy task if one wants to preserve the liquidity of exchanges.

By comparison, the priority system concentrates on the creation of a few well-chosen contingent assets, but these assets do not need to be exchanged on dedicated markets. Instead, what we have in mind is that a coarse set of prices could be set ex-ante by a regulatory authority. Basically, the authority would define a few priority classes, say A, B, and C. Each farmer would pay ex-ante a high price $p_{A}$ for a unit of water in class $\mathrm{A}$, a medium price $p_{B}$ for a unit of water in class $\mathrm{B}$, and a low price $p_{C}$ for a unit of water in class $\mathrm{C}$.

\footnotetext{
${ }^{6}$ Dinar and Mody (2003) survey factors that prevent water markets from becoming more widespread. In addition, in many countries farmers are used to paying very low prices (Bazzani et al, 2002, Hamdy, 2002).
} 
Ex-post, the available water supply would be measured and made available by the authority. Units in class A would be delivered first, followed by class B and then C. Finally, if supply falls short of fully supplying the marginal priority class, then a uniform rationing system could be applied. ${ }^{7}$ The point here is that the task of setting prices ex-ante is not too difficult: the regulator could, for example, aim at a balanced division of total demand across the three classes.

Moreover, the regulatory authority would make it clear when each priority class is served or not, thereby creating a contractible variable to be used by private insurers. Insurance subscription should be encouraged ex-ante, so as to avoid inheriting contentious situations ex-post. Once more, the key is to having farmers make suitable decisions ex-ante, knowing that in the future water might be scarce.

Our analysis has also shown that the efficiency result for a priority system relies on a symmetry assumption: climate shocks must affect farmers similarly. This is linked to the nature of the system: by organizing a simple queue, the system assumes that the needs of two different farmers are ranked in a stable way, whatever the final state of nature. We gave assumptions under which this property holds, the simplest one being that the basin is small enough.

We acknowledge that a smaller basin also means a smaller number of farmers, and therefore that market power may play an interesting role, both for the ex-post spot market and for the ex-ante mechanism for allocating seats in the queue for water. In both cases, one could allocate private endowments cleverly as in Hahn (1984), so as to neutralize market power. The comparison between the market system and the priority class system then hinges on whether a spot market or a market for seats is more vulnerable to the exercise of market power, which is an open and interesting question that we leave for

\footnotetext{
${ }^{7}$ Such a coarse system is also envisioned in Wilson (1989, Proposition 3, page 22). In particular, it is shown in that paper that the efficiency loss varies with the inverse of the square of the number of priority classes.
} 
future research.

We have focused on a single-period model. The extension to multiple periods raises the question of complexity: can farmers order water in advance, taking into account that the irrigation season (typically from two to four

months) is divided into periods of, say, fifteen days each? This difficulty is alleviated if one recognizes that crops registered as high or medium priority should logically be registered as such for the whole season. Hence, for these crops the farmer would have to estimate the water needs at each period, and buy the corresponding quantities in the same class, whatever the period.

In a nutshell, compared to a market system the priority class system mainly works ex-ante, and thus limits renegotiations in case of crisis; has a simple and robust design; allows for insurance; and preserves efficiency, by dedicating the use of irrigation water to the farmers that are most productive. Nevertheless, although our simple model encapsulates these important effects, several limitations should be pointed out. An important one is that individual extraction has to be monitored precisely. In practice, one easily observes whether a farmer irrigates or not, but getting a precise estimation of the volumes is not easy. We also acknowledge that the dynamics of irrigation are not modeled, though we are confident that our main results would extend. Finally, and maybe more importantly, we do not take into account irrigation water networks. These networks significantly increase the capacity to cope with climate shocks, but their funding and development is costly, and a study of cost allocation should be a part of future analysis.

\section{Data Availability Statement}

The data that support the findings of this study are openly available in Propluvia at

http://propluvia.developpement-durable.gouv.fr/propluvia/faces/index.jsp or directly from the authors. 


\section{References}

[1] Astier, N. (2021). "Second-Best Pricing for Incomplete Market sSegments: Application to Electricity Pricing, Journal of Public Economic Theory ttps://doi.org/10.1111/jpet.12499.

[2] Barbier, Edward B. (2019). The Water Paradox: Overcoming the Global Crisis in Water Management. Yale University Press.

[3] Bates, B.C., Kundzevicz, Z.W., Wu, S. and J.P. Palutikof (2008). "Climate Change and Water", Technical report, IPCC Secretariat, Geneva, 210 pp.

[4] Bazzani, G. M., S. Di Pasquale, V. Gallerani, and D. Viaggi (2004), "Irrigated Agriculture in Italy and Water Regulation under the European Union Water Framework Directive", Water Resources Research 40, W07S04.

[5] Beenstock, M. and G. Ephraim (1997). "Priority Pricing in Electricity Supply: An Application for Israel", Resource and Energy Economics 19 (3), 175-189.

[6] Berbel, J., M. M. Borrego-Martin, A. Exposito, G. Giannoccaro, N. M. Montilla-Lopez and C. Roseta-Palma, 2019. "Analysis of Irrigation Water Tarrifs and Taxes in Europe", Water Policy 21, 806-825.

[7] Bjornlund, H. and J. McKay (2002). "Aspects of Water Markets for Developing Countries: Experiences from Australia, Chile, and the US", Environment and Development Economics 7, 769-795.

[8] Bontems, P. and Nauges, C. (2019). "Production Choices with Water Markets and Risk Aversion: The Role of Initial Allocations and Forward Trading", European Review of Agricultural Economics 46 (4), 579-608.

[9] Chao, H. and R. Wilson (1987). "Priority Service: Pricing, Investment, and Market Organization", American Economic Review 77(5), 899-916. 
[10] Davidson, B., P. Hellegers and R. E. Namara, 2019. "Why Irrigation Water Pricing is Not Widely Used", Current Opinion in Environmental Sustainability 40, 1-6.

[11] Dinar, A. and J. Mody (2004). "Irrigation Water Management Policies: Allocation and Pricing Principles and Implementation Experiences", Natural Resources Forum 28 (2), 112-122.

[12] Crampes, C. and Y. Lefouili (2019). "Service Priority in the Electrical Industry", available at https://www.tse-fr.eu/service-priority-electricalindustry?lang=en.

[13] European Commission (EC), 2013. "Principles and Recommendations for integrating Climate Change Adaptation Considerations under the 2014-2020 Programmes". SWD 139 Final (Brussels).

[14] European Environmental Agency (EEA), 2012. "Climate Change, Impact and Vulnerability in Europe in 2012: an Indicator-Based Report" no 12, EEA, Copenhagen.

[15] Erdlenbruch, K., Loubier, S., Montginoul, M., Morardet, S. and M. Lefebvre (2013). "La Gestion du Manque d'Eau Structurel et des Sécheresses en France", Sciences Eaux $\mathcal{E}$ Territoires 11, 78-85.

[16] FAO, 2012. Coping with Water Scarcity: An Action Framework for Agriculture and Food Security," Technical Report.

[17] Gershkov, A. and E. Winter (2020). "Exploitative Priority Service", Discussion Paper, available at http://pluto.huji.ac.il/ alexg/pdf/priority6.pdf.

[18] Grafton, R. Q., Horn, J. and S. A. Wheel (2015). "On the Marketisation of Water: Evidence from the Murray-Darling Basin, Australia", Water Resource Management 30, 913-926. 
[19] Hagerty, N., 2019. Liquid Constrained in California: Estimating the Potential Gains from Water Markets, Working Paper, available at https://economics.mit.edu/files/14178.

[20] Hahn, Robert W. (1984). "Market Power and Transferable Property Rights", The Quarterly Journal of Economics 99(4), 753-765.

[21] Hamdy, A. (2002). "Water Pricing in Agricultural Sector Charging Mechanisms and Implementation", http://www.worldbank.org/agadirconference.

[22] Hornbeck, R. and P. Keskin (2014). "The Historically Evolving Impact of the Ogallala Aqifer: Agricultural Adaptation to Groundwater and Drought", American Economic Journal: Applied Economics 6 (1), 190219.

[23] Howitt, R. (1998). "Spot Prices, Option Prices, and Water Markets: An Analysis of Emerging Markets in California", Volume 15 of the series Natural Resource Management and Policy, pp. 119-140. Editors: K. William Easter, Mark W. Rosegrant, Ariel Dinar.

[24] Johansson, R. C. , Tsur, Y., Roe, T. L., Doukkali, R. and A. Dinar (2002). "Pricing Irrigation Water: a Review of Theory and Practice", Water Policy 4 (2), 173-199.

[25] Intergovernmental Panel on Climate Change (IPCC), 2014. Summary for policymakers. In: Climate Change 2014: Impacts, Adaptation, and Vulnerability. Part A: Global and Sectoral Aspects. Contribution of Working Group II to the Fifth Assessment Report of the Intergovernmental Panel on Climate Change [Field, C.B., V.R. Barros, D.J. Dokken, K.J. Mach, M.D. Mastrandrea, T.E. Bilir, M. Chatterjee, K.L. Ebi, Y.O. Estrada, R.C. Genova, B. Girma, E.S. Kissel, A.N. Levy, S. MacCracken, P.R. Mastrandrea, and L.L. White (eds.)]. Cambridge University Press, Cambridge, United Kingdom and New York, NY, USA, pp. 1-32. 
[26] Kahil, M. H., Connor, J. D. and J. Albiac (2015). "Efficient Water Management Policies for Irrigation Adaptation to Climate Change in Southern Europe", Ecological Economics 120, 226-233.

[27] Le Breton, M. and F. Salanié (2003). "Lobbying under Political Uncertainty", Journal of Public Economics 87(12), 2589-2610.

[28] Lefebvre, M., Thoyer, S. and M. Willinger (2009), "Risk-sharing Rules for Water Allocation in Drought Periods. Recommendations for French Water Policy Reform",

[29] Lefebvre, M., Thoyer, S., Tidball, M. and M. Willinger (2014). "Sharing Rules for Common-Pool Resources When Self-Insurance is Available: an Application to Water Management in France", Environmental Modeling E Assessment 19 (2), 111-125.

[30] Lund, J. R. and R. M. Reed (1995). "Drought Water Rationing and Transferable Rationing", Journal of Water Resources Management and Planning 121 (6), 429-437.

[31] Rafey, W. (2019). "Droughts, Deluges, and (river) Diversions: Valuing Market-Based Water Reallocation", Working Paper, available at https://economics.mit.edu/grad/rafey/research.

[32] Strauss, T. and S. Oren (1993). "Priority Pricing of Interruptible Electric Service with an Early Notification Option", The Energy Journal 14 (2), 175-196.

[33] UN (2012). Managing Water under Uncertainty and Risk, The United Nations World Water Development Report 4 (1), Paris: UNESCO.

[34] UN (2015). Water for a Sustainable World, The United Nations World Water Development Report 2015, Paris: UNESCO.

[35] Wilson, R. (1989). "Efficient and Competitive Rationing", Econometrica 57(1), 1-40. 
[36] Woo, C. (1994) "Managing Water Supply Shortage. Interruption vs. Pricing", Journal of Public Economics 54(1), 145-160. 


\section{Appendix}

Proof of the claim in section 2: consider the problem

$$
\max _{x} E B(k x Q, x)
$$

where we omit the variables $s$ and $\theta$ for clarity. The cross-derivative in $(k, x)$ is

$$
Q B_{q}+x Q\left(k Q B_{q q}+B_{q x}\right)
$$

and by setting $q=k x Q$, we obtain:

$$
Q\left(B_{q}(q, x)+q B_{q q}(q, x)+x B_{x q}(q, x)\right)
$$

which is positive under (1). This shows that the function $B(k x, x)$ is supermodular in $(k, x)$, and this implies that the solution to problem (12) is increasing with $k$. Therefore, (4) has a unique solution in $X$, as announced in the text.

Note also that from the identity $B_{q}(D)=p$ we readily obtain $B_{q q} D_{p}=1$ and $B_{q q} D_{x}+B_{q x}=0$, so that the condition $B_{q}+q B_{q q}+x B_{x q} \geq 0$ reduces to $p D_{p}+D-x D_{x} \leq 0$, or equivalently $1 \leq \varepsilon_{p}+\varepsilon_{x}$. This is the property on elasticities announced in the text.

Finally, notice that if $B$ is homogenous of degree $h>0$, i.e., $B(\alpha q, \alpha x)=$ $\alpha^{h} B(q, x)$, then thanks to the Euler's homogenous function theorem we get

$$
q B_{q}+x B_{x}=(q, x) \cdot \nabla B(q, x)=h B(q, x)
$$

Because $B$ increases with $q$, this shows property (1) in this case.

Proof of Proposition 2: a) The efficient decisions are characterized as follows. We have:

$$
q^{*}(\theta, s)=a(\theta) x^{*}(\theta) d\left(p^{*}(s), s\right)
$$

and therefore the resource constraint yields

$$
d\left(p^{*}(s), s\right)=\frac{Q(s)}{X_{a}^{*}}
$$


where $X_{a}^{*}$ is the average irrigated area in terms of efficiency units:

$$
X_{a}^{*}=\int a(\theta) x^{*}(\theta) d F(\theta) .
$$

Therefore each efficient quantity can be computed as a share of total available quantity:

$$
q^{*}(\theta, s)=\frac{a(\theta) x^{*}(\theta)}{X_{a}^{*}} Q(s) .
$$

Moreover, each farmer ends up maximizing on $x$ the profit

$$
a(\theta) x E\left[b\left(d\left(p^{*}(s), s\right), s\right)-p^{*}(s) d\left(p^{*}(s), s\right)\right]-\theta c(x),
$$

so that the individual irrigated area is characterized by:

$$
c_{x}\left(x^{*}(\theta), \theta\right)=a(\theta) E \beta\left(\frac{Q(s)}{X_{a}^{*}}, s\right),
$$

where

$$
\beta(d, s)=b(d, s)-d b_{1}(d, s) .
$$

Because $\beta$ increases with $d$, this system of equations in fact uniquely characterizes the area $x^{*}(\theta)$ chosen by each farmer $\theta$. Because $a(\theta) / \theta$ is decreasing with $\theta$ and $c$ is convex, we obtain that $x^{*}(\theta)$ decreases with $\theta$. A fortiori, $q^{*}(\theta, s)$ also decreases with $\theta$. Overall, efficiency requires that farmers with higher types choose a lower risk-exposure, and consume a lower quantity of water with a lower density per unit of irrigated land, while the water density per efficiency unit of irrigated land is the same for all farmers.

b) Under uniform rationing, we have

$$
q^{R}(\theta, s)=\frac{x^{R}(\theta)}{X^{R}} Q(s) .
$$

One key difference with (15) is that efficiency equalizes water quantities per efficiency unit of irrigated land, while uniform rationing equalizes water quantities per unit of irrigated land. Uniform rationing is therefore inefficient, 
because it allocates too much water to some unproductive land units and not enough to more productive units. In addition, the irrigated area is chosen to maximize

$$
\left.a(\theta) x E b\left(\frac{Q(s)}{a(\theta) X^{R}}, s\right)\right)-c(x, \theta)
$$

so that the solution $x^{R}(\theta)$ must satisfy the following first-order condition:

$$
c_{x}\left(x^{R}(\theta), \theta\right)=a(\theta) E b\left(\frac{Q(s)}{a(\theta) X^{R}}, s\right) .
$$

To compare this condition with (16), define the function

$$
\varphi(x, \theta)=\frac{c_{x}(x, \theta)}{a(\theta)} .
$$

From our assumptions, $\varphi$ is increasing in $\theta$ and in $x$. (16) then implies that $x^{*}(\theta)$ is decreasing in $\theta$, as the term $E \beta$ is independent from $\theta$.

Under uniform rationing, the left-hand-side of (18) increases with $\theta$, as $c_{\theta x}>0$; and the right-hand-side is easily shown to be increasing in $a,{ }^{8}$, and therefore decreasing in $\theta$. Because the right-hand-side does not depend on $x$, and $c$ is convex in $x$, we obtain that $x^{R}(\theta)$ is also decreasing in $\theta$.

The water quantity per unit of irrigated land is $\frac{q^{R}(\theta, s)}{x^{R}(\theta)}=\frac{1}{X^{R}} Q(s)$, which is (by the very definition of uniform rationing) independent from $\theta$. Under efficiency, the water quantity per unit of irrigated land is

$$
\frac{q^{*}(\theta, s)}{x^{*}(\theta)}=\frac{a(\theta)}{\int a(t) x^{*}(t) d F(t)} Q(s),
$$

which decreases with $\theta$. As announced in the Proposition, the former is less than the latter if and only if $\theta \leq \theta_{2}$, where $\theta_{2}$ is characterized by:

$$
a\left(\theta_{2}\right) \equiv \frac{\int a(t) x^{*}(t) d F(t)}{X^{R}} .
$$

Finally, let $A^{*}=\varphi\left(x^{*}(\theta), \theta\right)$; note that from (16), this number is independent from $\theta$. Let $A_{R}(\theta)=\varphi\left(x^{R}(\theta), \theta\right)$; from (18), $A_{R}(\theta)$ is increasing with $\theta$.

\footnotetext{
${ }^{8}$ Indeed, the derivative w.r.t. $a$ is the expectation of $b(q)-q b_{1}(q)$, taken at $q=q^{R}$, which is positive by concavity of $b$.
} 
Because $\varphi$ increases with $x, x^{R}(\theta)$ is less than $x^{*}(\theta)$ if and only if $A_{R}(\theta)$ is less than $A^{*}$, and thus if and only if $\theta$ is less than some level $\theta_{1}$. Finally, at $\theta=\theta_{2}$ we have

$$
\begin{gathered}
A^{R}\left(\theta_{2}\right)=E b\left(\frac{Q(s)}{\int a(t) x^{*}(t) d F(t)}, s\right)=E b\left(d\left(p^{*}(s), s\right), s\right) \\
>A^{*}=E\left[b\left(d\left(p^{*}(s), s\right)-p^{*}(s) d\left(p^{*}(s), s\right)\right],\right.
\end{gathered}
$$

and therefore one must have $\theta_{1}<\theta_{2}$. This concludes the proof.

A discussion of the case when (10) holds. Under this condition, for every $s$ one has

$$
\int d\left(p^{*}(s), x^{*}(\theta), Q(s), \theta\right) d F(\theta)=Q(s)
$$

so that $p^{*}(s)$ is a function of $Q(s)$ only: $p^{*}(s)=\rho(Q(s))$. By differentiating the resource constraint, we get

$$
\rho^{\prime}(Q) \int d_{p} d F+\int d_{Q} d F=1
$$

Now, when $q^{*}(\theta, s)=d\left(\rho(Q(s)), x^{*}(\theta), Q(s), \theta\right)$, this quantity increases with $Q(s)$ if

$$
d_{p} \rho^{\prime}(Q)+d_{Q} \geq 0
$$

Replacing $\rho^{\prime}$ by its expression found above, and because $d_{p}<0$, this condition becomes:

$$
\frac{d_{Q}}{d_{p}}\left(p^{*}(s), x^{*}(\theta), Q(s), \theta\right) \leq \rho^{\prime}(Q)=\frac{\int d_{Q} d F}{\int d_{p} d F}+\frac{1}{-\int d_{p} d F} .
$$

The first term in the right hand side is an average of the ratios $d_{Q} / d_{p}$, with the positive weights $\left(-d_{p}\right)$. The second term is positive. This expression thus states that $d_{Q} / d_{p}$ is not too dependent on $(x, \theta)$, for each $Q(s)$. This holds in particular when this ratio is a constant, but then we are back to the other restriction (9). 